\title{
Enhancement of Transient Stability of the Nigeria 330 kV Transmission Network Using Fault Current Limiter
}

\author{
Ignatius K. Okakwu, Emmanuel A. Ogujor \\ Department of Electrical/Electronic Engineering, Faculty of Engineering, University of Benin, Benin City, Edo State, Nigeria \\ Email: igokakwu@yahoo.com
}

How to cite this paper: Okakwu, I.K. and Ogujor, E.A. (2017) Enhancement of Transient Stability of the Nigeria $330 \mathrm{kV}$ Transmission Network Using Fault Current Limiter. Journal of Power and Energy Engineering, 5, 92-103.

https://doi.org/10.4236/jpee.2017.59008

Received: August 8, 2017

Accepted: September 24, 2017

Published: September 27, 2017

Copyright ( 92017 by authors and Scientific Research Publishing Inc. This work is licensed under the Creative Commons Attribution International License (CC BY 4.0).

http://creativecommons.org/licenses/by/4.0/

\begin{abstract}
The dynamic responses of generators when subjected to disturbances in an interconnected power system have become a major challenge to power utility companies due to increasing stress on the power network. Since the occurrence of a disturbance or fault cannot be completely avoided, hence, when it occurs, control measures need to be put in place to limit the fault current, which invariably limit the level of the disturbances. This paper explores the use of Superconductor Fault Current Limiter (SFCL) to improve the transient stability of the Nigeria $330 \mathrm{kV}$ Transmission Network. During a large disturbance, the rotor angle of the generator is enhanced by connecting a Fault Current Limiter (FCL) which reduces the fault current and hence, increases transient stability of the power network. In this study, the most affected generator was taken into consideration in locating the $S F C L$. The result obtained reveals that the Swing Curve of the generator without FCL increases monotonically which indicates instability, while the Swing Curve of the System with FCL reaches steady state.
\end{abstract}

\section{Keywords}

Transient Stability, Fault Current Limiter, Nigeria 330 kV, Power System

\section{Introduction}

Although, the occurrence of disturbances within power networks cannot be avoided, its impact which undermines the security margin of the system could be minimized. This usually resulted to the instability in the operation of power systems. This challenge therefore poses a great concern to power system researchers recently. In resolving this issue, there is the need to evaluate the ability and response of a power network when subjected to various disturbances with 
the aim of maintaining the network reliability. Instability in power system networks is of various types based on the duration. When a power system is subjected to a disturbance, the network may experience loss of synchronism which could result to total voltage collapse within the network. This explains why transient stability enhancement is of paramount importance in the operation of power system. Different techniques for enhancing transient stability of a multi-machine power system have been proposed in the literature [1]. These techniques include: reduction in system transfer reactance, use of breaking resistor, use of bundled conductor, use of fault current limiter and the placement of FACTS devices [2]. As the power network becomes more complex, the consequence is that the fault current increases, and transient stability problem becomes more severe. The use of fault current limiter (FCL) has been identified as one of the necessary elements required to limit the fault current and invariably enhance the power system transient stability [3]. On the other hand, superconductor fault current limiter ( $S F C L$ ) plays a better role in limiting fault current during fault. $S F C L$ offers low impedance (near zero) during normal operation, hence, does not interfere during steady state operation of the system. In the event of a fault, the $S F C L$ quenches and this phenomenon causes a fast raise of the limiter impedance up to a value needed for limiting the fault current. The impedance of $S F C L$ can change the transient stability of power system [4]. The presence of $S F C L$ in a power system can improve the system stability and distributed energy quality [5].

In the literatures, a number of studies have so far been done on transient stability improvement of power systems. Sheeba et al. [6] use FCL and SVC to enhance transient stability of IEEE 59-bus test system using ETAP Software. Masaki et al. [7] investigates the effect of FCL and Thyristor Controlled Braking Resistor (TCBR) on transient stability of IEEE 9-bus test system. Byung et al. [8], this paper describes the optimal sizing of a Resistive Superconducting Fault Current Limiter (RSFCL) applied to a multi-machine power system. The optimized $S F C L$ generally gives the best damping performance for low-frequency oscillations. Heresh et al. [9] presents the application of FCL for reduction of fault current in a high voltage substation. Fereidouni et al. [10] evaluated the effects of the use of Solid-State Fault Current Limiter (SSFCL) unit on the transient stability of power systems and power quality. This paper focuses on the improvement of transient stability of the Nigeria $330 \mathrm{kV}$ transmission network using Inductive-Type Superconductor Fault Current Limiter (ISFCL).

\section{The Nigeria $330 \mathrm{kV}$ Transmission Network}

The Nigeria $330 \mathrm{kV}$ transmission network used as the case study in this paper is shown in Figure 1. It consists of eleven (11) generators, twenty-one (21) load buses and thirty-six (36) transmission lines, which cut across the six (6) Geo-political zone (South-West, South-South, South-East, North-Central, North-West and North-East Region) of the country with long radial interconnected transmission lines as depicted in Figure 1. 


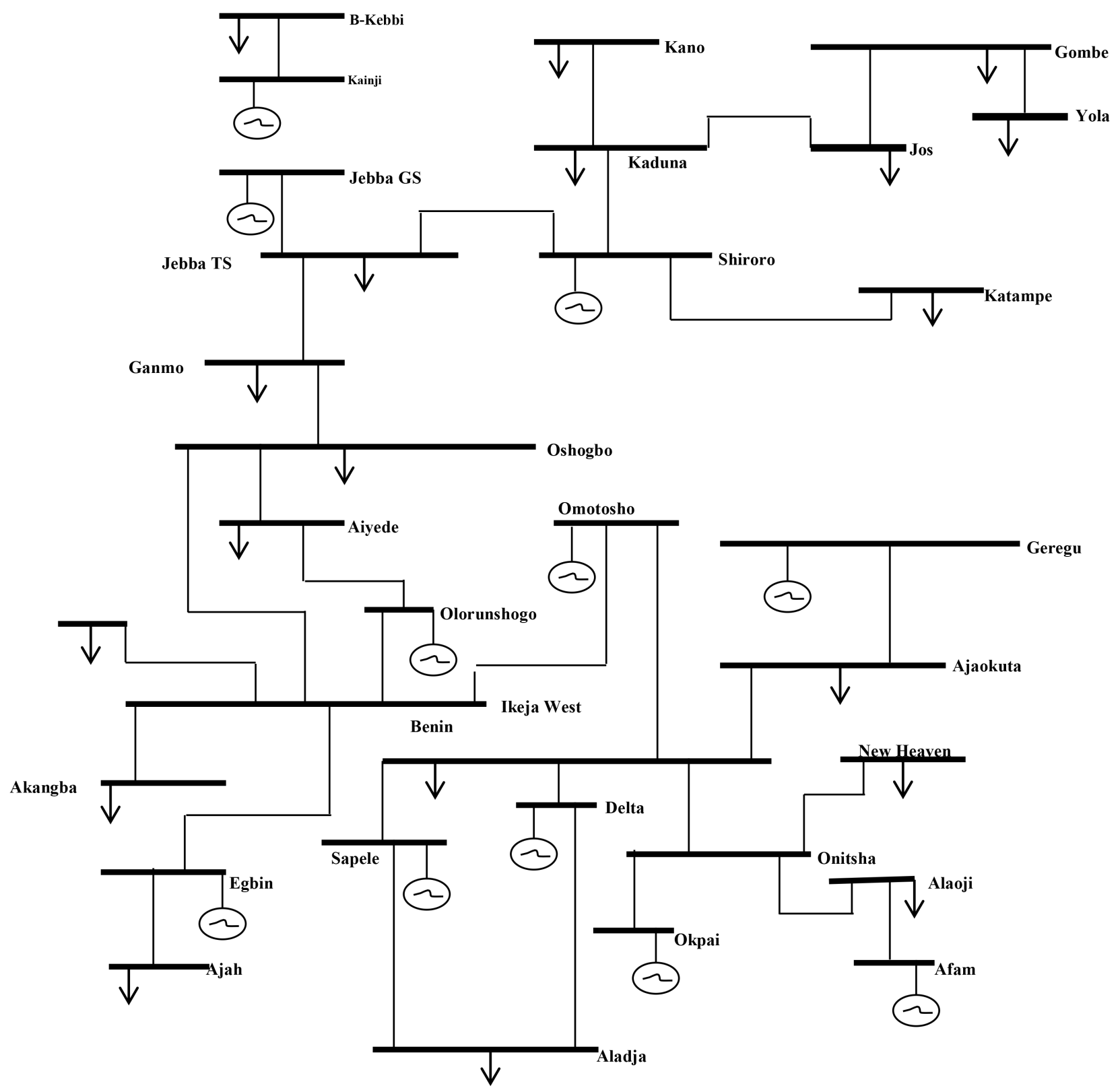

Figure 1. Single line diagram of the Nigeria $330 \mathrm{kV}$ transmission network.

The Nigeria $330 \mathrm{kV}$ grid network is becoming more complex due to the recent deregulation in the Power Sector of the Economy to meet the ever-increasing energy demand [11]. Due to varying load demand, fragile nature of the transmission network, lack of sensitive equipment and frequent outages due to disturbances which result to instability. Assessing the network performance will involve system stability studies. System Stability may involve transient stability studies on the network.

\section{Mathematical Modeling of a Multi-Machine Transient Stability Analysis}

Consider a multi-machine $n$-bus power network consisting of $m$ number of ge- 
nerators such that $n>m$. At any bus $i$ within the system, the complex voltages $\left(V_{i}\right)$, generators real power $\left(P_{g i}\right)$ and the generator reactive power $\left(Q_{g i}\right)$ can easily be obtained from the pre-fault load-flow analysis from which the initial machine voltages $\left(E_{i}\right)$ can also be obtained. This relationship can be expressed as [12]

$$
E_{i}=V_{i}+j X_{i}\left[\frac{P_{g i}-j Q_{g i}}{V_{i}^{*}}\right]
$$

where

$X_{\mathrm{i}}$ is the equivalent reactance at bus $i$.

By converting each load bus into its equivalent constant admittance form, we have [13]

$$
Y_{L i}=\frac{P_{L i}-j Q_{L j}}{\left|V_{i}\right|^{2}}
$$

where $P_{L i}$ and $Q_{L i}$ are the respective equivalent real and reactive powers at each load bus.

The pre-fault bus admittance matrix $\left[Y_{\text {bus }}\right]$ can therefore be formed with the inclusion of generators reactance and the converted load admittance. This can be partition as [14]:

$$
Y_{\text {bus }}=\left[\begin{array}{ll}
Y_{11} & Y_{12} \\
Y_{21} & Y_{22}
\end{array}\right]
$$

where $Y_{11}, Y_{12}, Y_{21}$ and $Y_{22}$, are the sub-matrices of $Y_{\text {bus }}$. Out of these four sub-matrices, $Y_{11}$, whose dimension is $m \times m$ is the main interest of this paper as it contains generator buses only with the load buses eliminated.

Equation (3) is formulated for the network conditions such as pre-fault, during fault and post-fault. The $Y_{\text {bus }}$ for the network is then formulated by eliminating all nodes except the internal generator nodes. The reduction is achieved based on the fact that injections at all load nodes are zero. The nodal equations, in compact form, can therefore be express as [15]

$$
\left[\begin{array}{l}
1 \\
0
\end{array}\right]=\left[\begin{array}{ll}
Y_{m m} & Y_{m n} \\
Y_{n m} & Y_{n n}
\end{array}\right]\left[\begin{array}{l}
V_{m} \\
V_{n}
\end{array}\right]
$$

By expansion, Equation (4) can be expanded as

$$
I_{m}=Y_{m m} V_{m}+Y_{m n} V_{n}
$$

and

$$
0=Y_{n m} V_{m}+Y_{n n} V_{n}
$$

By combining Equation (5) and Equation (6) and some mathematical manipulations, the desired reduced admittance matrix can be obtained as

$$
Y_{\text {reduced }}=Y_{m m}-Y_{m n} Y_{n n}^{-1} Y_{n m}
$$

$Y_{\text {reduced }}$ is the desired reduced matrix with dimension $m \times m$, where $m$ is the number of generators.

The electrical power output of each machine can then be written as [16] 


$$
P_{e i}=E_{i}^{2} Y_{i i} \cos \theta_{i i}+\sum_{\substack{i=1 \\ j \neq i}}^{m}\left|E_{i}\right|\left|E_{j}\right|\left|Y_{i j}\right| \operatorname{Cos}\left(\theta_{i j}-\delta_{i}+\delta_{j}\right)
$$

Equation (8) is use to determine the electrical power output of the generator during fault $P_{e i}\left(P_{e i(\text { during-fault })}\right)$ and post-fault $P_{e i}\left(P_{e i(\text { during-fault })}\right)$ conditions.

The rotor dynamics, representing the swing equation, at any bus $i$, is given by

$$
\frac{H_{i}}{\pi f_{o}} \frac{\mathrm{d}^{2} \delta_{i}}{\mathrm{~d} t^{2}}+D_{i} \frac{\mathrm{d}_{i}}{\mathrm{~d} t}=P_{m i}-P_{e i}
$$

All the parameters retain their usual meanings.

Consider a case when there is no damping i.e. $D_{i}=0$, Equation (9) can be re-written as [17]

$$
\frac{H_{i}}{\pi f_{o}} \frac{\mathrm{d}^{2} \delta_{i}}{\mathrm{~d} t^{2}}=P_{m i}-\left(E_{i}^{2} Y_{i i} \cos \theta_{i i}+\sum_{\substack{i=1 \\ j \neq i}}^{m}\left|E_{i}\right|\left|E_{j}\right|\left|Y_{i j}\right| \operatorname{Cos}\left(\theta_{i j}-\delta_{i}+\delta_{j}\right)\right)
$$

$\therefore$ The swing equation for the during-fault condition can easily be express as

$$
\frac{H_{i}}{\pi f_{o}} \frac{\mathrm{d}^{2} \delta_{i}}{\mathrm{~d} t^{2}}=P_{m i}-P_{\text {ei(during-fault })}
$$

Similarly, the swing equation for the post fault condition can be written as

$$
\frac{H_{i}}{\pi f_{o}} \frac{\mathrm{d}^{2} \delta_{i}}{\mathrm{~d} t^{2}}=P_{m i}-P_{\text {ei (post-fault })}
$$

\section{Modeling of Inductive-Type Superconductor Fault Current Limiter}

The FCL consist of a controller, a detector and a limiting resistance/reactance that helps to limit fault current during fault and improve the transient stability of power system. Figure 2 shows the variation of the limiting resistance with time.

The limiting resistance value is assume to be $1 \mathrm{p} \cdot \mathrm{u}$ and the fault detection time and starting of the limiting resistance are $2 \mathrm{~ms}$ and $1 \mathrm{~ms}$ respectively. This means FCL starts to operate at $0.102 \mathrm{sec}$, and then the limiting resistance increases linearly from $0.0 \mathrm{p} \cdot \mathrm{u}$ to $1.0 \mathrm{p} \cdot \mathrm{u}$ within $1 \mathrm{~ms}$.

Consider a synchronous generator connected to an infinite bus system as shown in Figure 3.

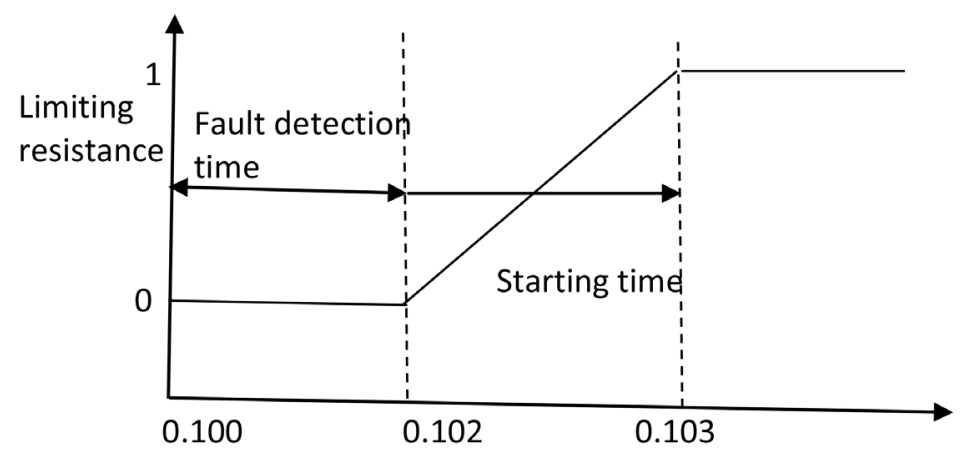

Figure 2. FCL characteristics. 


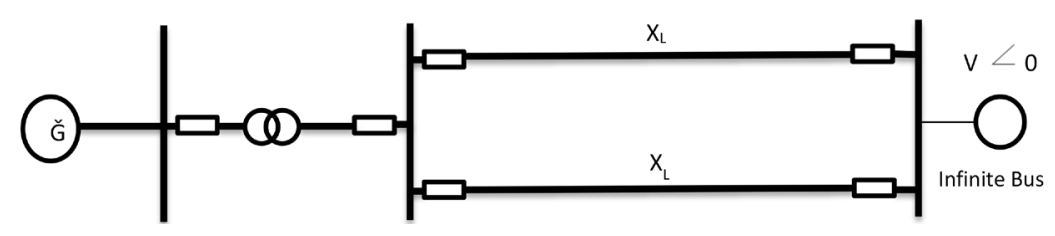

Figure 3. Single machine infinite bus.

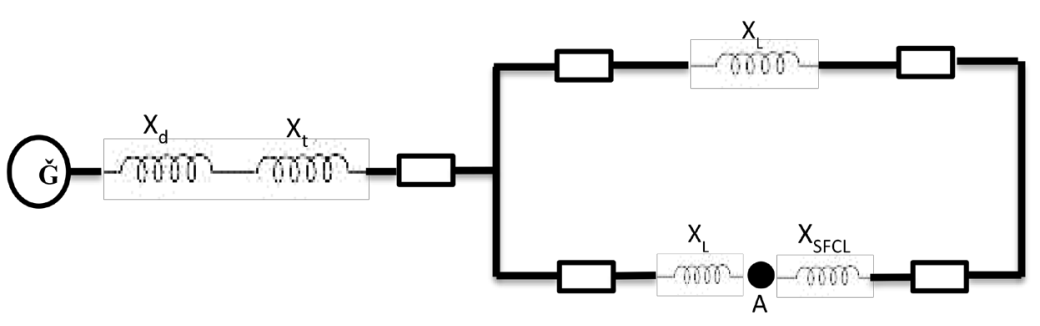

Figure 4. ISFCL installed in a line feeder.

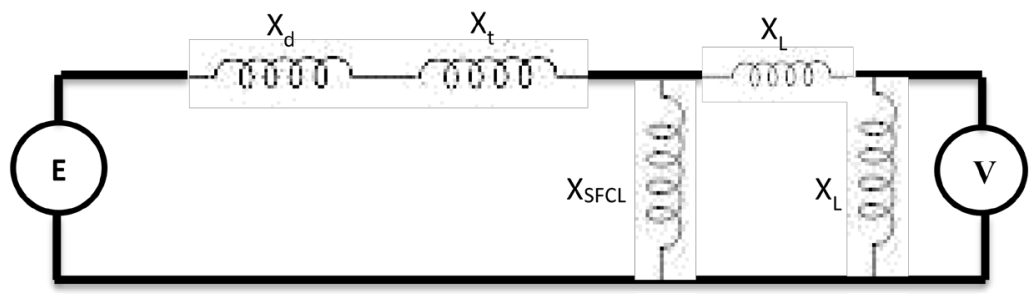

Figure 5. Equivalent circuit when ISFCL is installed in line feeder.

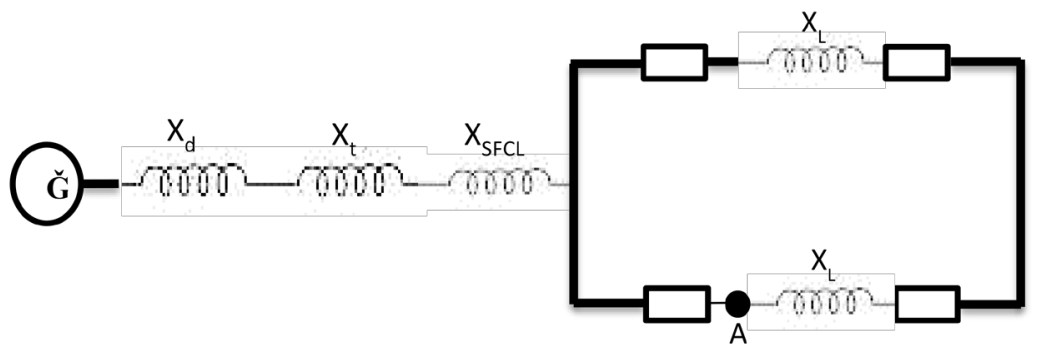

Figure 6. Equivalent circuit when ISFCL is installed in generator-transformer feeder.

The maximum power transferred from the generator to the system is given by a well-known expression:

$$
\begin{gathered}
P_{\max }=\frac{|V||E|}{X_{e q}} \operatorname{Sin} \delta \\
X_{e q}=X_{d}+X_{t}+\frac{X_{L}}{2}
\end{gathered}
$$

where $X_{d}=$ reactance of generator, $X_{t}=$ reactance of transformer, $X_{L}=$ reactance of line.

Note that the values of resistances are small when compared with inductances; hence, all resistances are negligible.

Also, consider ISFCL installed in a line feeder of Figure 3 as shown in Figure 4.

The equivalent circuit is shown below in Figure 5.

Using Delta-star transformation, the equivalent reactance obtained during fault 
is given by Equation (14):

$$
X_{e q}=X_{d}+X_{t}+X_{L}+\frac{\left(X_{d}+X_{t}\right)+X_{L}}{X_{S F C L}}
$$

When the fault is cleared after opening the breaker, the equivalent reactance obtained after fault is given by Equation (15):

$$
X_{e a}=X_{d}+X_{t}+X_{L}
$$

Furthermore, with ISFCL installed in the generator-transformer feeder, the equivalent circuit is shown in Figure 6.

In the case of a 3-phase fault at point $\mathrm{A}$, the power transfer during fault is equal to zero. The equivalent reactance obtained after fault is cleared by opening of breaker is given by Equation (16):

$$
X_{e q}=X_{d}+X_{t}+X_{S F C L}+X_{L}
$$

Comparing Equation (15) and Equation (16) shows that installation of ISFCL in the line feeder enhances transient stability better than ISFCL installed in generator-transformer feeder.

\section{Results and Discussion}

Figure 7 and Figure 8 shows the swing curves for all the ten generators in the Nigeria $330 \mathrm{kV}$ transmission network when a three-phase fault occurs at Aiyede bus (Bus 16).

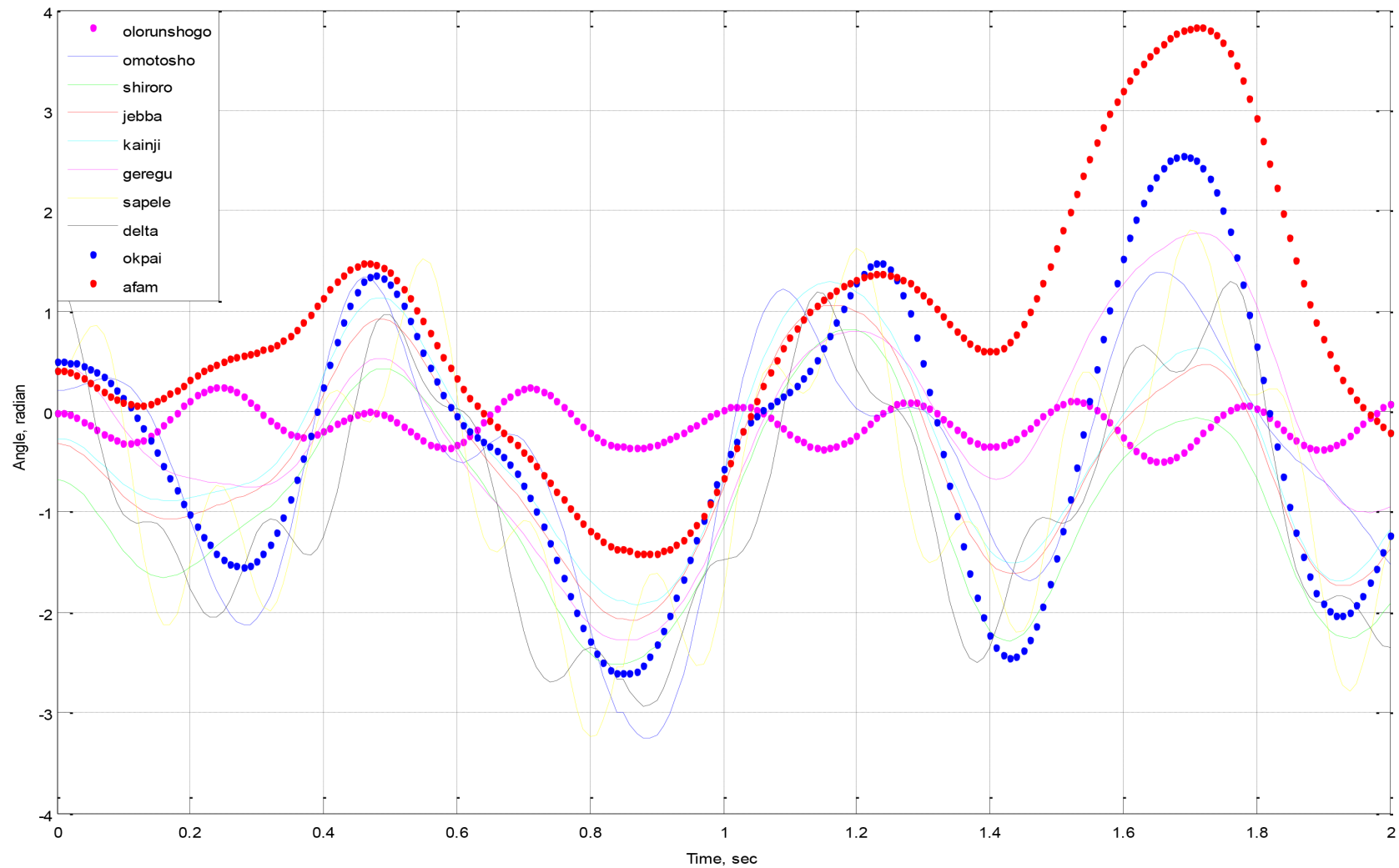

Figure 7. Rotor angle for a three-phase fault on bus 16 , with line $16-2$ removed $(\mathrm{CCT}=840 \mathrm{~ms})$. 


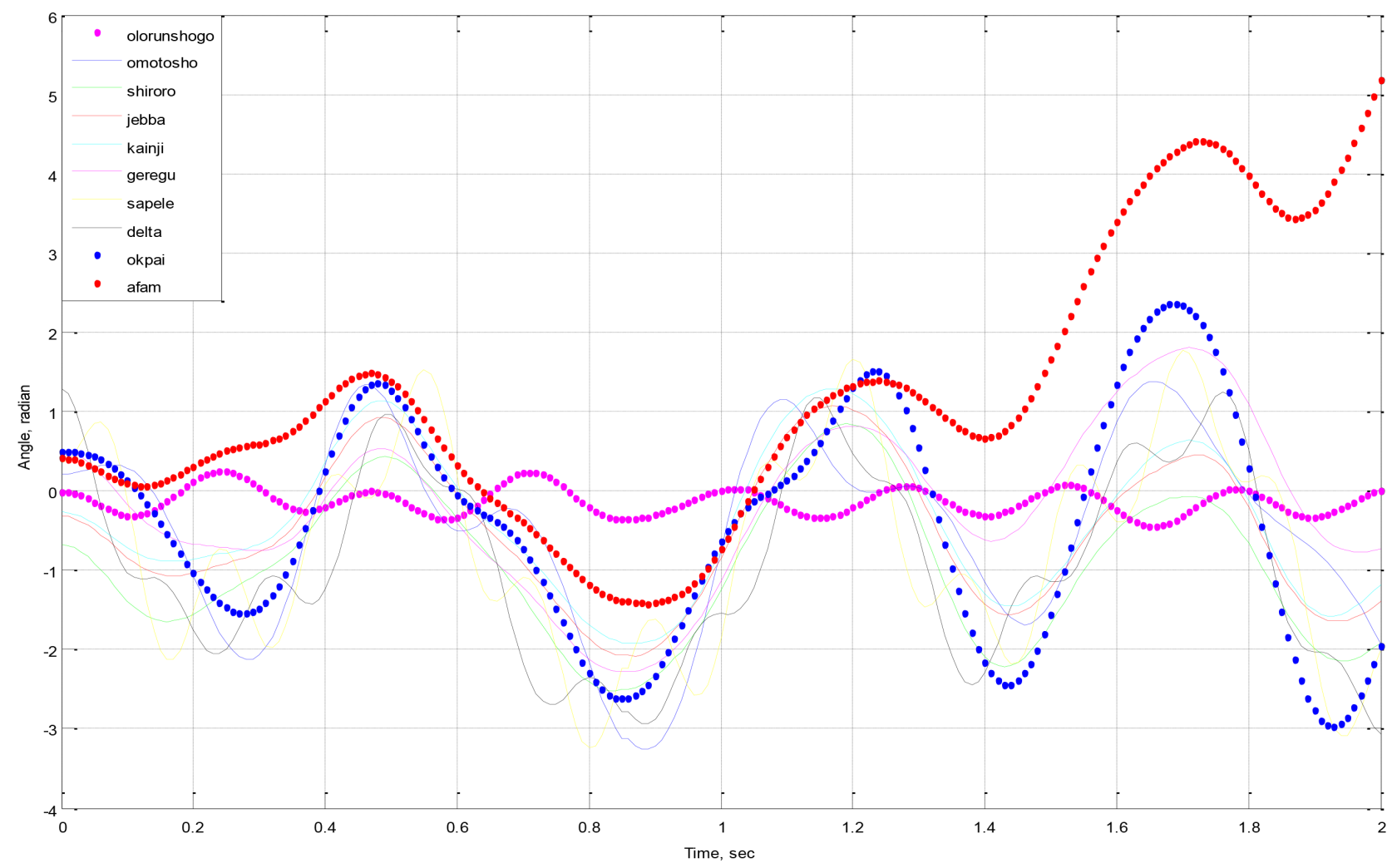

Figure 8. Rotor angle for a three-phase fault on bus 16, with line 16-2 removed (CCT $=850 \mathrm{~ms}$ ).

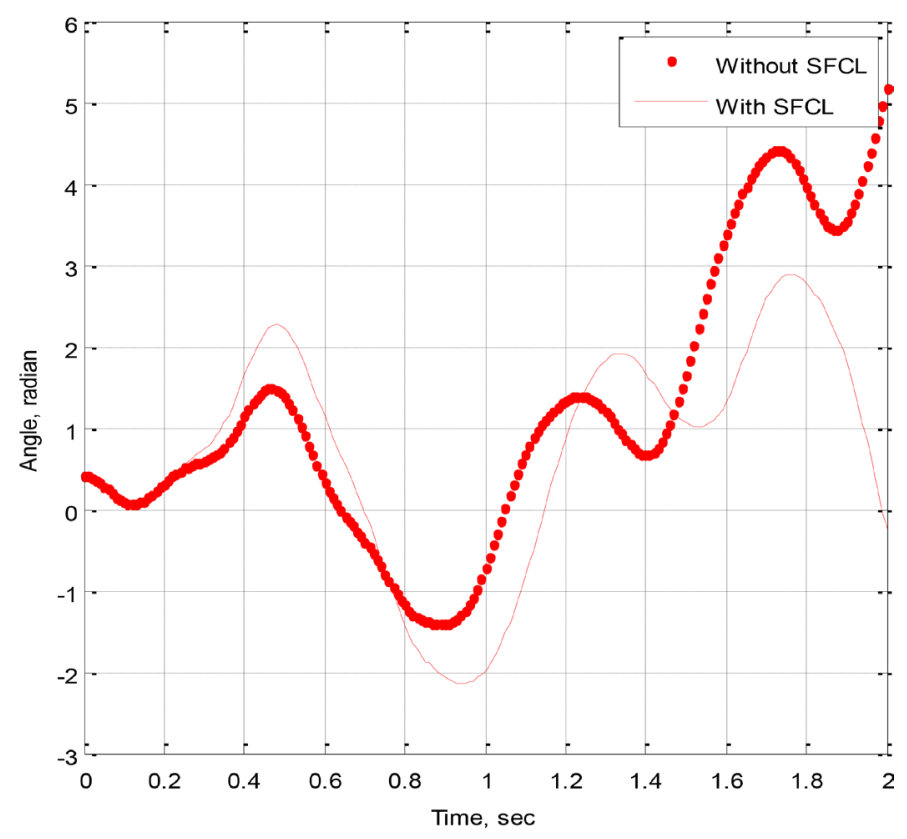

Figure 9. Swing curve of generator at Afam with line 16-2 removed, with ISFCL installed in line 11-29 $(\mathrm{CCT}=850 \mathrm{~ms})$.

It is observed from the swing curve of Figure 7 and Figure 8 that only the generator at Afam is the most severely disturbed, hence, the only generator considered for the investigation of the effect of ISFCL on the power system. It is 


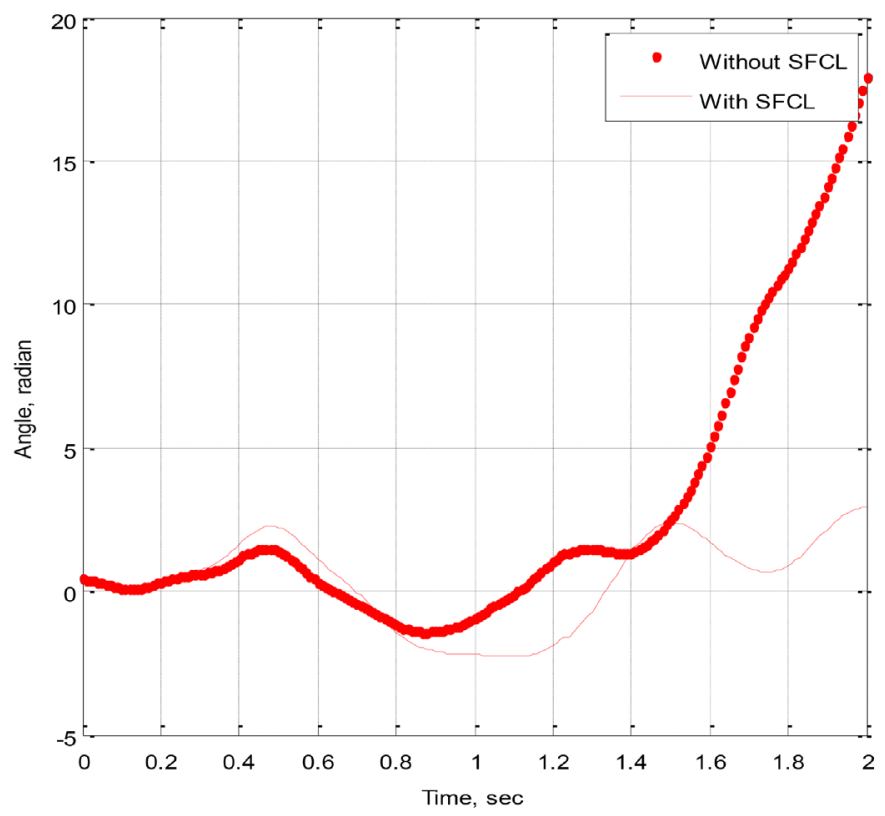

Figure 10. Swing curve of generator at Afam with line 16-2 removed, with ISFCL installed in line 11-29 (CCT = $1230 \mathrm{~ms})$.

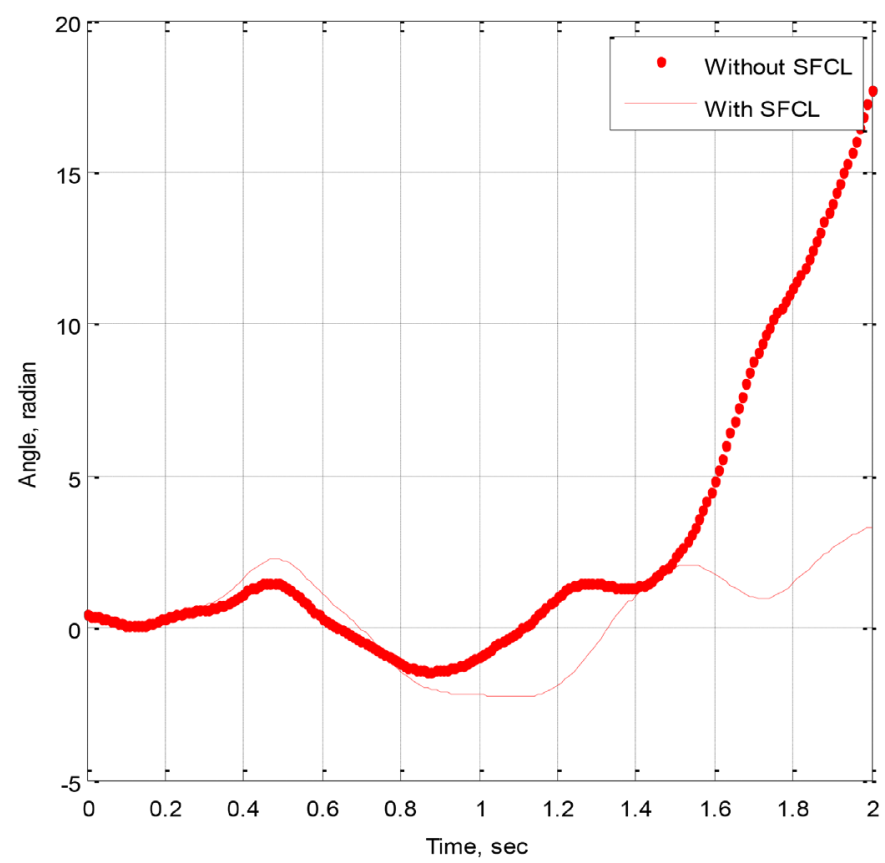

Figure 11. Swing curve of generator at Afam with Line 16-2 removed, with ISFCL installed in line 11-29 (CCT = $1380 \mathrm{~ms})$.

clearly seen from Figure 8 that when a three-phase fault was created at bus 16 (Aiyede), the system becomes unstable for a fault clearing time of $850 \mathrm{~ms}$. But with the installation of $S F C L$ between line $11-29$, as clearly seen from Figures 9-13, the fault clearing time was increased to $1390 \mathrm{~ms}$ after which synchronism was lost. The present of the FCL was able to damp low-frequency oscillation in the power network. 


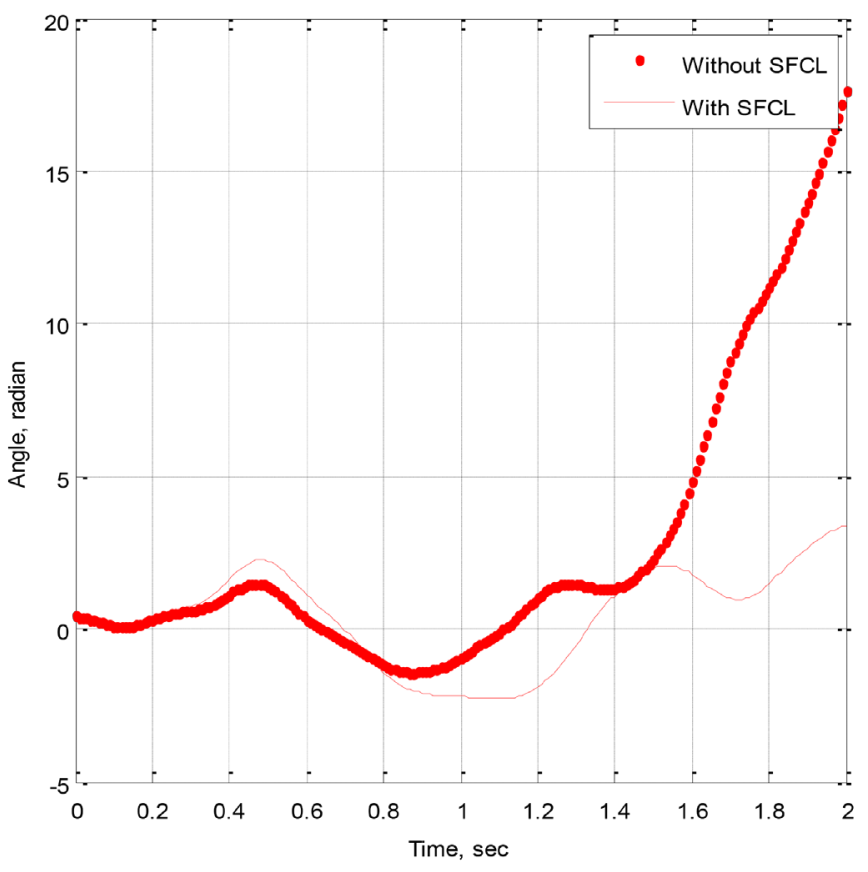

Figure 12. Swing curve of generator at Afam with line 16-2 removed, with ISFCL installed in line 11-29 (CCT = $1390 \mathrm{~ms})$.

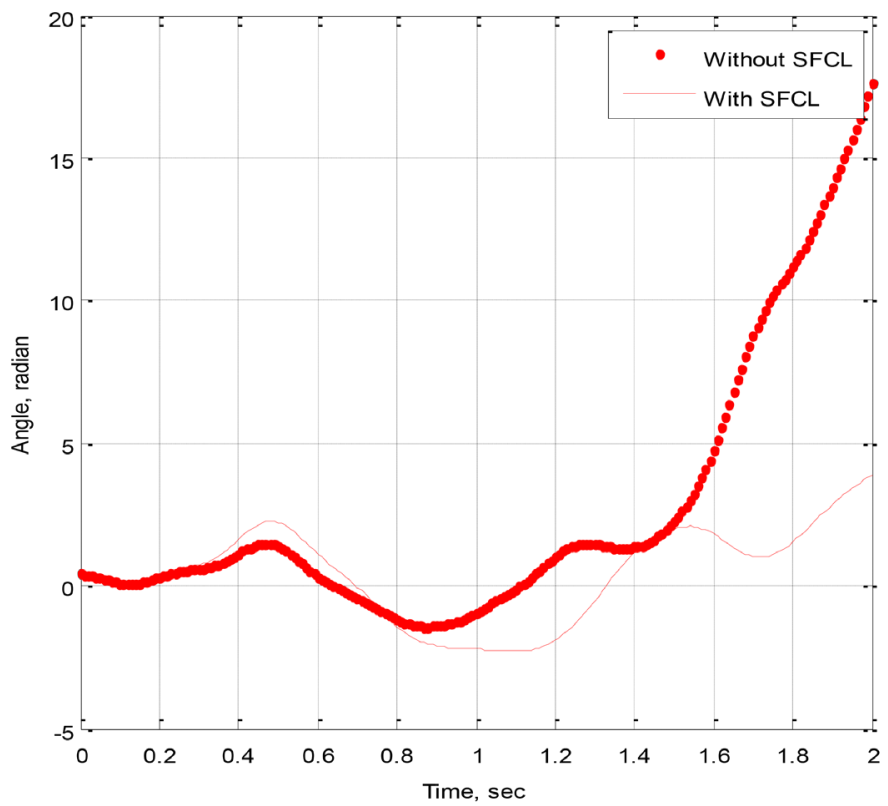

Figure 13. Swing curve of generator at Afam with line 16-2 removed, with ISFCL installed in line 11-29 (CCT $=1400 \mathrm{~ms})$.

\section{Conclusion}

In this paper, an investigation of the effectiveness of superconductor fault current limiter in enhancing transient stability of the Nigeria $330 \mathrm{kV}$ grid network is presented. The result reveals that when a three-phase fault is created at Aiyede bus, the generator at Afam generating station was found to loss synchronism at 
$850 \mathrm{~ms}$, but with the installation of $S F C L$, the critical clearing time was improved to $1390 \mathrm{~ms}$, which shows an improvement of $65.48 \%$. Thus, there is considerable improvement in the generator rotor angle and rotor speed.

\section{References}

[1] Srinvasa, J. and Amarnath, J. (2014) Enhancement of transient Stability in Aderegulated Power System Using FACTS Devices. Global Journal of Researches in Engineering, 14, 1-17.

[2] Rani, A. and Arul, P. (2013) Transient Stability Enhancement of Multi-Machine Power System Using UPFC and SSSC. International Journal of Innovative Technology and Exploring Engineering, 3, 77-81.

[3] Masaki, Y. and Junji, Y. (2010) Enhancement of Transient Stability Using Fault Current Limiter and Thyristor Controlled Breaking Resistor. IEE Xplore, 1-6.

[4] Sagar, N., Pavan, G. and Rajalakshmi, M. (2016) Transient Stability Analysis of IEEE 59 Bus System with FCL and SVC Controller Using ETAP. Journal of Chemical and Pharmaceutical Sciences, 2016, 248-251.

[5] Sravani, T., Hari, G. and Basha, J. (2010) Improvement of Power System Stability Using SFCL in Elastic Power Grid under Voltage Unbalance Conditions. International Journal of Emerging Trends in Electrical and Electronics, 10, 80-89.

[6] Sheeba, P. and Brindha, H. (2016) Transient Stability Enhancement in a Distribution Network Using FCL and SVC. International Journal of Electrical and Electronics Research, 4, 143-157.

[7] Yagami, M. and Tamura, J. (2009) Power System Stabilization by Fault Current Limiter and Thyristor Controlled Braking Resistor. IEEE Xplore, 548-553.

[8] Chul, B. and Park, J. (2014) A Study on Optimization of Resistive SFCL for Multi-Machine Power System Using Eigenvalue Analysis. Journal of International Council on Electrical Engineering, 4, 167-172. https://doi.org/10.5370/JICEE.2014.4.2.167

[9] Seyedi, H. and Tabei, B. (2012) Appropriate Placement of Fault Current Limiting Reactors in Different HV Substation Arrangements. Circuits and Systems, 3, 252-262. https://doi.org/10.4236/cs.2012.33035

[10] Fereidouni, A.R., Vahidi, B., Hoseini, T. and Garmroodi, M. (2011) Enhancement of Power System Transient Stability and Power Quality Using a Novel Solid-State Fault Current Limiter. Journal of Electrical Engineering \& Technology, 6, 474-483. https://doi.org/10.5370/JEET.2011.6.4.474

[11] Omorogiuwa, E. and Onohaebi, S.O. (2015) Optimal Location of IPFC in Nigeria $330 \mathrm{kV}$ Integrated Power Network Using Ga Technique. Journal of Electrical \& Electronic Systems, 4, 1-8.

[12] Harvinderpal, S. and Prince, J. (2016) Enhancement of Multi-Machine Stability Using Fault Current Limiter and Thyristor Controlled Braking Resistor. International Journal of Modern Computer Science, 14, 28-31.

[13] Mohamed, M. and Mohamed, A. (2014) Enhancement of Multi-Machine Power System Transient Stability using Superconducting Fault Current Limiters with YBCO and Bi-2212. International Journal on Power Engineering and Energy, 5, 48-423.

[14] Tarafdar, M., Naderi, S. and Jafari, N. (2011) Improvement of Power System Stability Using a Controllable Resistor Type Fault Current Limiter. International Conference in Power Systems Transient, 14-17. 
[15] Ravi, S. and Nagaraju, S. (2010) Transient Stability Improvement Using UPFC and SVC. ARPN Journal of Engineering and Applied Sciences, 2, 38-45.

[16] Nwohu, M.N., Isah, A., Usman, A.U. and Sadiq, A.A. (2016) Optimal Placement of Thyristor Controlled Series Compensator (TCSC) on Nigerian 330 kV Transmission Grid to Minimize Real Power Losses. International Journal of Research Studies in Electrical and Electronics Engineering, 2, 18-26.

[17] Yasima, M.N. and Al-eedanya, M. (2013) Enhancement of Power System Transient Stability Using SVC. International Journal of Current Engineering and Technology, $3,1-8$.

Submit or recommend next manuscript to SCIRP and we will provide best service for you:

Accepting pre-submission inquiries through Email, Facebook, LinkedIn, Twitter, etc. A wide selection of journals (inclusive of 9 subjects, more than 200 journals) Providing 24-hour high-quality service

User-friendly online submission system

Fair and swift peer-review system

Efficient typesetting and proofreading procedure

Display of the result of downloads and visits, as well as the number of cited articles Maximum dissemination of your research work

Submit your manuscript at: http://papersubmission.scirp.org/

Or contact jpee@scirp.org 